\title{
Paediatric Crossword Puzzle 22
}

\section{Manouri Senanayake ${ }^{1}$}

Sri Lanka Journal of Child Health, 2014; 43(1): 65

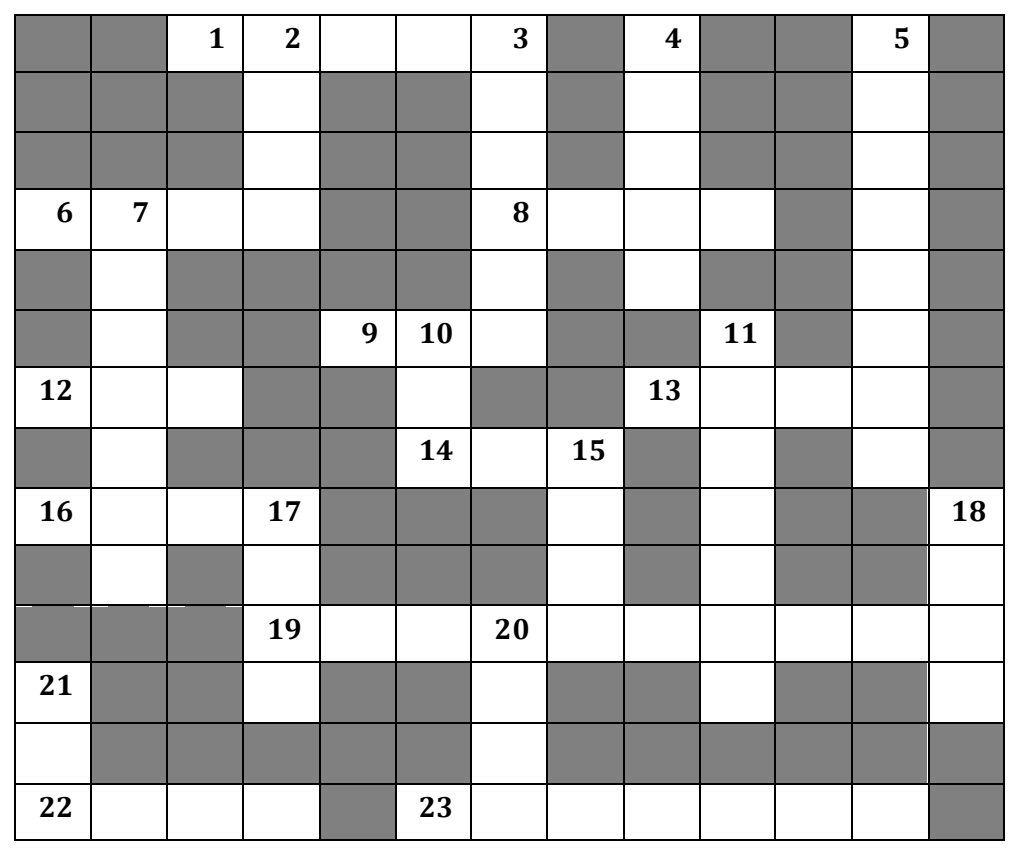

\section{Across}

01. Respiration in diabetic ketoacidosis is deep and --

06. The monospot test for EBV is an improvement on the -------- Bunnell test.

08. Most sensitive test to assess hearing of newborn (abbrv)

09. Clitoromegaly in the newborn is clitoral length more than------------- $\mathrm{cm}$

12. Exclusive breast feeding is until ---------completed months

13. In neonatal resuscitation correct face mask size should cover nose, mouth and

14. Most common site used for central venous access (abbrv)

16. Age in months by when healthy infant is able to sit unsupported

19. White reflex in pupil

22. Quality of attachment when more areola is seen above than below the mouth

23. A food item that commonly causes carotenaemia in infants in Sri Lanka

\section{Down}

02. Cutaneous reflex that is lost due to spinal cord lesion at S 2-4

03. Dentition in Hyper lgE syndrome

04. Palmer grasp disappears by ------- months

05. Speech centers are in the ---------- hemisphere

07. $\mathrm{Z}$ technique is used to insert needle in -.-.-. aspiration

10. Synonymous with Battered Baby Syndrome (abbrv)

11. Respiration in narcotic overdose is regular and ---

15. Abnormal pharyngeal arch development causes -----cardio facial syndrome

17. Anesthetic cream applied to skin before venepuncture

18. Labia majora in extreme prematurity

20. Kidney disease increasing in incidence in Sri Lanka

21. An investigation that is decreasing in use for diagnosis of brain tumors and strokes 